\title{
The Unusually High Proton Affinity of Aza-18-Crown-6 Ether: Implications for the Molecular Recognition of Lysine in Peptides by Lariat Crown Ethers
}

\author{
Ryan R. Julian and Jesse L. Beauchamp \\ Beckman Institute, California Institute of Technology, Pasadena, California, USA
}

\begin{abstract}
Recent studies have shown that 18-crown-6 ether (18C6) will selectively form adducts in the gas phase with small, lysine containing peptides. The present study extends this work by investigating the ability of aza-18-crown-6 ether (A18C6) and L1 (a simple lariat crown ether derivative of A18C6) to form similar noncovalent adducts with the side chain of lysine in model peptides in the gas phase. The substitution of nitrogen for oxygen greatly increases the proton affinity of A18C 6 relative to 18C6 and inhibits the formation of noncovalent adducts with small lysine containing peptides. The proton affinity of A18C6 is determined by the kinetic method to be $250 \pm 1 \mathrm{kcal} / \mathrm{mol}$. This value is much higher than that for diethanolamine $(228 \mathrm{kcal} / \mathrm{mol})$ or for $18 \mathrm{C} 6(231 \mathrm{kcal} / \mathrm{mol})$. This unusually high basicity is rationalized by semi-empirical calculations that suggest a highly symmetrical structure for protonated A18C6 in which the three most distant oxygens are able to fold back and hydrogen bond with the protonated nitrogen. In the case of L1, the lariat side chain is attached by an amide bond, lowering the proton affinity of L1 relative to that of A18C6. This allows L1 to form noncovalent adducts with lysine despite the fact that steric repulsion within the cavity of the crown is increased to some extent. The relative ammonium ion affinities of these various crown ethers are shown to serve as qualitative predictors for the molecular recognition of lysine. The order of the relative ammonium ion affinities is $18 \mathrm{C} 6 \gg \mathrm{L} 1>\mathrm{A} 18 \mathrm{C} 6$ as determined by the kinetic method. These results suggest that the substitution of nitrogen for oxygen in the crown ether is not beneficial for the molecular recognition of lysine. (J Am Soc Mass Spectrom 2002, 13, 493-498) @ 2002 American Society for Mass Spectrometry
\end{abstract}

$\mathrm{T}$ The study of supramolecular chemistry by mass spectrometry in the gas phase is rapidly expanding [1]. Self complementary molecular assemblies have been used to encapsulate a variety of ionic guests [2]. The macrobicyclic cryptate effect has been demonstrated for cryptands complexed with various metal ion guests in the gas phase [3]. Other studies have shown that chirality can affect the noncovalent supramolecular association of amino acids into clusters [4]. Crown ethers have been studied extensively due to their ability to bind metal cations [5]. The ability of crown ethers, particularly 18-crown-6 (18C6), to complex with ammonium [6] or alkylammonium [7] ions in the gas phase has also been demonstrated. We have recently applied this property of $18 \mathrm{C} 6$ to the molecular recognition of the biologically important amino acid lysine in small peptides and proteins [8].

Published online March 27, 2002

Address reprint requests to Dr. Jesse L. Beauchamp, Department of Chemistry, Beckman Institute, California Institute of Technology, M/C 127-72, Pasadena, California 91125, USA. E-mail: jlbchamp@its.caltech.edu
It would be useful to combine the molecular recognition of 18C6 with the added chemical functionality available in lariat crown ethers (crown ethers with a side chain covalently attached) [9]. Such lariat crown ethers would have increased chemical tunability and could be used to initiate or mediate chemical reactions with biological species in a site selective manner by utilizing the molecular recognition of lysine. For example, it might be possible to initiate the gas phase cleavage of peptide bonds in the vicinity of lysine residues with an appropriate lariat crown ether. The most common motifs for making lariat crown ethers are depicted as Type I and Type II below. Type II lariat crown ethers are by far the most common due to the extra bond afforded by the nitrogen heteroatom. Type II lariat crown ethers are flexible, allowing the side chain to interact with either face of the crown cavity [10]. Type II lariat crown ethers also avoid the generation of the chiral center which complicates the synthesis of Type I lariat crowns [11]. This suggests that the interaction of aza-18-crown-6 (A18C6) and Type II lariat crown ethers with lysine should be investigated to 
determine if the molecular recognition abilities of $18 \mathrm{C} 6$ can be coupled with the added functionality of lariat crown ethers.

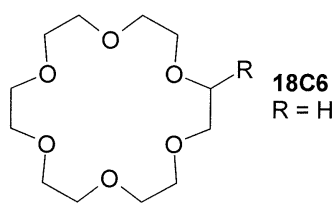

Type I

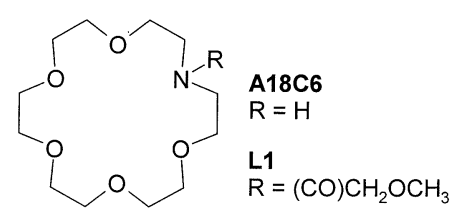

Type II
In the present work, the molecular recognition capabilities of A18C6 and L1 are compared with those of 18C6. A18C6 does not demonstrate the molecular recognition of lysine that is observed for 18C6. This is attributed to the high proton affinity of A18C6, which serves to preferentially remove a proton from any alkyl ammonium ion upon introduction to the gas phase. The proton affinity of A18C6 is determined by the kinetic method to be $250 \pm 1 \mathrm{kcal} / \mathrm{mol}$ [12]. Semi-empirical calculations suggest a highly symmetrical structure for protonated A18C6 in which the three most distant oxygens are able to fold back and hydrogen bond with the protonated nitrogen. L1, by contrast, has a lower proton affinity than A18C6 and forms noncovalent adducts with the side chain of lysine. However, the relative abundance of the noncovalent adducts of L1 with lysine is small in comparison with 18C6. The relative affinities of A18C6, L1, and $18 \mathrm{C} 6$ for the ammonium ion are determined by the kinetic method [12]. The order of the relative ammonium ion affinities is $18 \mathrm{C} 6 \gg \mathrm{L} 1>\mathrm{A} 18 \mathrm{C} 6$, which is representative of the ability of each crown to form noncovalent adducts with lysine. The implications of these results for the design of lariat crown ethers capable of interacting with lysine are discussed.

\section{Methods}

All data were obtained using a Finnigan LCQ (San Jose, CA) ion trap quadrupole mass spectrometer without modification. Soft sampling is crucial for the detection of these non-covalent complexes. The critical instrument settings that yield adduct formation include capillary voltage $14.12 \mathrm{~V}$, capillary temperature $200{ }^{\circ} \mathrm{C}$, and tube lens offset $-39 \mathrm{~V}$. Higher capillary temperatures dissociate the crown ether/peptide complexes. The tube lens offset controls the acceleration of ions as they leave the capillary region. The tube lens voltage is minimized to avoid collisions with the He buffer gas. For the proton affinity experiments, the capillary temperature was reduced to $140{ }^{\circ} \mathrm{C}$ and up to $1 \%(\mathrm{v} / \mathrm{v})$ acetic acid was added to the mixture. The standard kinetic method was applied to measure the proton affinity of A18C6 [13]. 1,1,3,3 tetramethylguanidine (TMG), 1,5-Diazabicyclo[4.3.0]non-5-ene (DBN), 1,8Diazabicyclo[5.4.0] undec-7-ene (DBU), 1,3,4,6,7,8-Hexahydro-1-methyl-2H-pyrimido[1,2-a]pyrimidine (HMPP), and 1,3,4,6,7,8-Hexahydro-2H-pyrimido[1,2-a]pyrimidine (HPP) were used as the reference bases.

Sample concentrations were typically kept in the $\sim 10$ to $100 \mu \mathrm{M}$ range for all species of interest, unless otherwise noted. All samples were electrosprayed in a mixture of 80:20 methanol/water. Crown ethers were added to the sample and electrosprayed with the analyte in order to observe adducts. Samples were electrosprayed with a flow of 3-5 $\mu \mathrm{L} / \mathrm{min}$ from a $500 \mu \mathrm{L}$ Hamilton syringe for optimal signal. Silica tubing with an inner diameter of $0.005 \mathrm{in}$. was used as the electrospray tip. No acid was added to any of the samples, unless otherwise noted. All chemicals unless otherwise noted were purchased from Sigma or Aldrich and used without further purification. L1 was synthesized by the dropwise addition of methoxy acetyl chloride (CAS 38870-89-2) to A18C6 in dichloromethane with one equivalent of triethylamine. The mixture was refluxed for four hours and the solvent was removed under a flow of dry nitrogen. The ratio of product to starting material was approximately $5: 1$, from analysis of the mass spectrum of the crude reaction mixture, indicating a reasonable yield.

All semi-empirical calculations were performed with the HyperChem 5.1 Professional Suite. Candidate structures were identified with molecular mechanics using Cerius $^{2}$ version 4.0 by Molecular Simulations Inc. with the Dreiding 2.21 [14] force field. Structures were fully optimized at the PM3 semi-empirical level.

\section{Results and Discussion}

To determine if Type II lariat crown ethers can specifically bind to lysine, we choose A18C6 as the simplest model compound and examined a mixture of A18C6 with tetralysine. The results are compared with those for 18C6. Figure 1a shows the electrospray mass spectrum for tetralysine under typical conditions with the addition of $0.1 \%(\mathrm{v} / \mathrm{v})$ acetic acid. The peptide is primarily doubly charged, although a there are significant contributions from the triply and singly charged peaks as well. When 18C6 is added to the solution as shown in Figure $1 \mathrm{~b}$, the multiply-charged, multiple adduct $\left[\mathrm{K}^{4}+4(18 \mathrm{C} 6)+4 \mathrm{H}\right]^{4+}$ is the base peak. This spectrum demonstrates the excellent molecular recognition and charge stabilization capabilities of 18C6, which have been examined in greater detail previously [8]. In contrast, the addition of A18C6 to a solution of tetralysine does not result in the formation of a noncovalently bound crown/peptide adduct peak (Figure 1c). Furthermore, the doubly and triply charged tetralysine peaks present in Figure 1a are not detected in Figure 1c, and the singly charged $[\mathrm{A} 18 \mathrm{C} 6+\mathrm{H}]^{+}$peak dominates the spectrum. Through the replacement of one oxygen by nitrogen, A18C6 has effectively lost the ability of 18C6 to form stable supramolecular complexes with protonated lysine residues in peptides. The two primary factors that account for this observation are discussed below. 

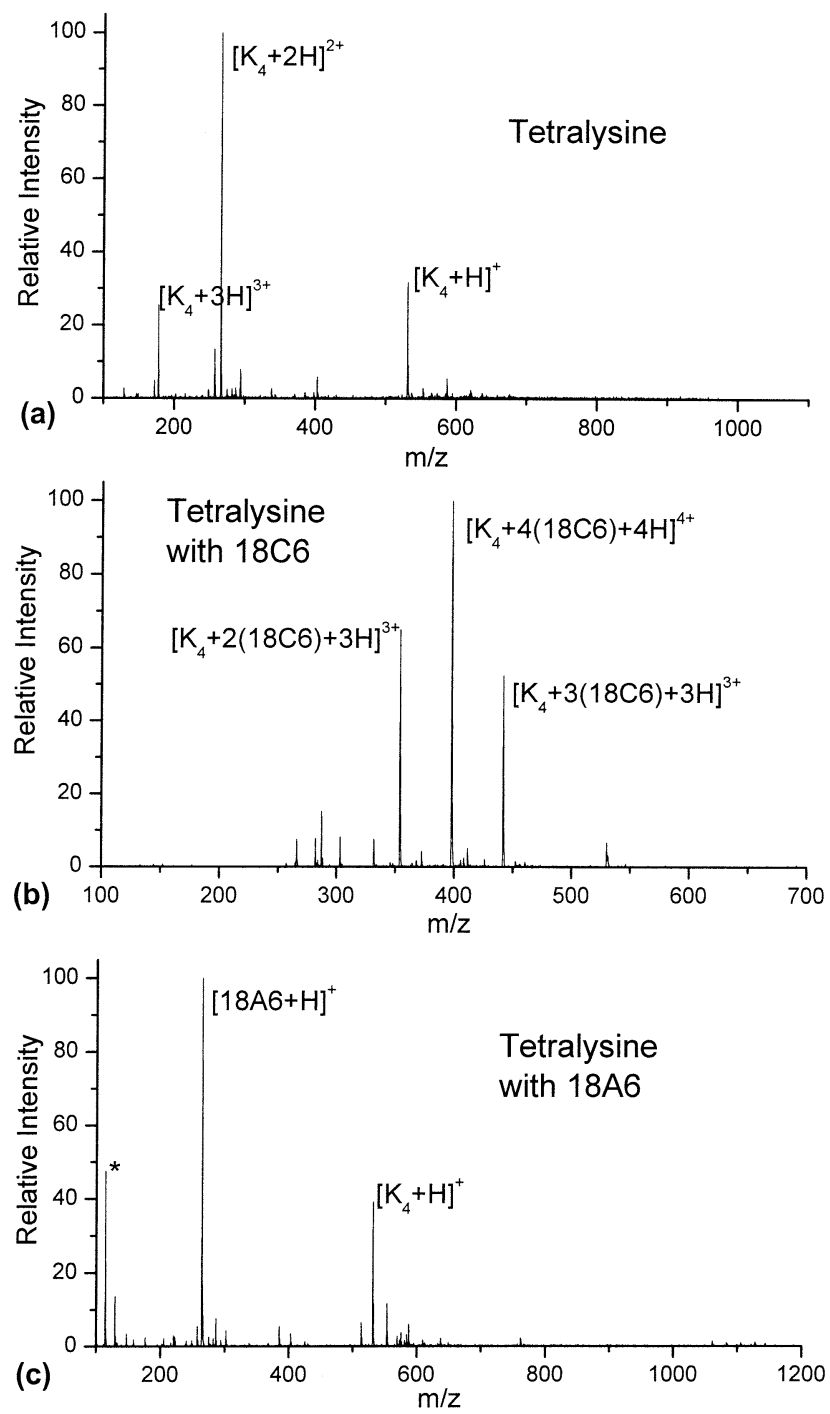

Figure 1. (a) Electrospray mass spectrum of tetralysine under typical conditions. (b) ESI-MS of a mixture of tetralysine and 18C6, demonstrating abundant noncovalent molecular cluster formation. (c) ESI-MS of tetralysine with A18C6. No adduct formation is observed. Asterisk corresponds to an A18C6 fragment.

\section{High Proton Affinity of A18C6}

Clearly, the nitrogen present in A18C6 will raise the proton affinity of this compound higher than that of 18C6. The standard kinetic method [12] was employed to determine the proton affinity of A18C6. The structures and abbreviations for the reference bases are given in Scheme 1. The collision-induced dissociation (CID) of the proton bound dimer $[\mathrm{A} 18 \mathrm{C} 6+\mathrm{H}+\mathrm{DBU}]^{+}$shown in Figure 2 is representative of the data collected for this experiment. No other dissociation pathways were ob-<smiles>C1CCN=C2NCCCN2CC1</smiles><smiles>c1ncc2c(n1)CCCN2</smiles>

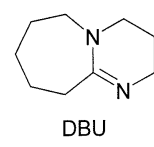

Scheme 1

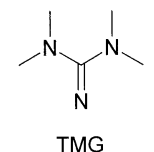

TMG

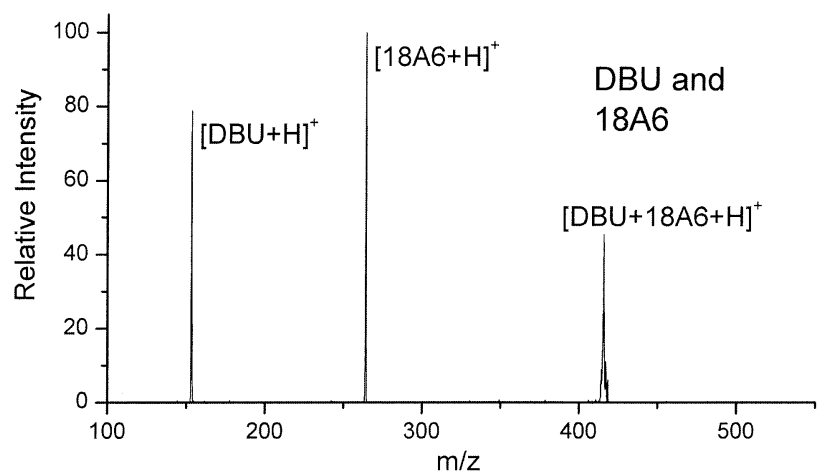

Figure 2. Example of data used to determine the proton affinity of A18C6 by the kinetic method. The dissociation of $[\mathrm{DBU}+\mathrm{A} 18 \mathrm{C} 6+\mathrm{H}]^{+}$is shown.

served for any of the dimers, and changing the collision energy did not significantly alter the product distribution. The plot of the $\ln \left([\mathrm{A} 18 \mathrm{C} 6+\mathrm{H}]^{+} /[\mathrm{Ref}+\mathrm{H}]^{+}\right)$versus the proton affinity of the reference compounds is shown in Figure 3. From the data in Figure 3, the proton affinity for A18C6 is determined to be $250 \pm 1 \mathrm{kcal} / \mathrm{mol}$. It has been pointed out that caution should be utilized when employing the kinetic method with multidentate ligands because entropic effects for different dissociation pathways are not accounted for [15]. However, the basicity of the nitrogen heteroatom will localize the extra proton in the case of A18C6, limiting any entropic effects which would require special consideration.

The proton affinity of A18C6 is nearly $20 \mathrm{kcal} / \mathrm{mol}$ higher than the proton affinity of $18 \mathrm{C} 6$. The proton affinity of diethyl amine is $227.6 \mathrm{kcal} / \mathrm{mol}$, and the addition of two oxygens in diethanolamine $(228 \mathrm{kcal} /$ $\mathrm{mol}$ ) does not significantly raise the proton affinity of that compound. There are no other single nitrogen containing secondary amines within at least $10 \mathrm{kcal} /$

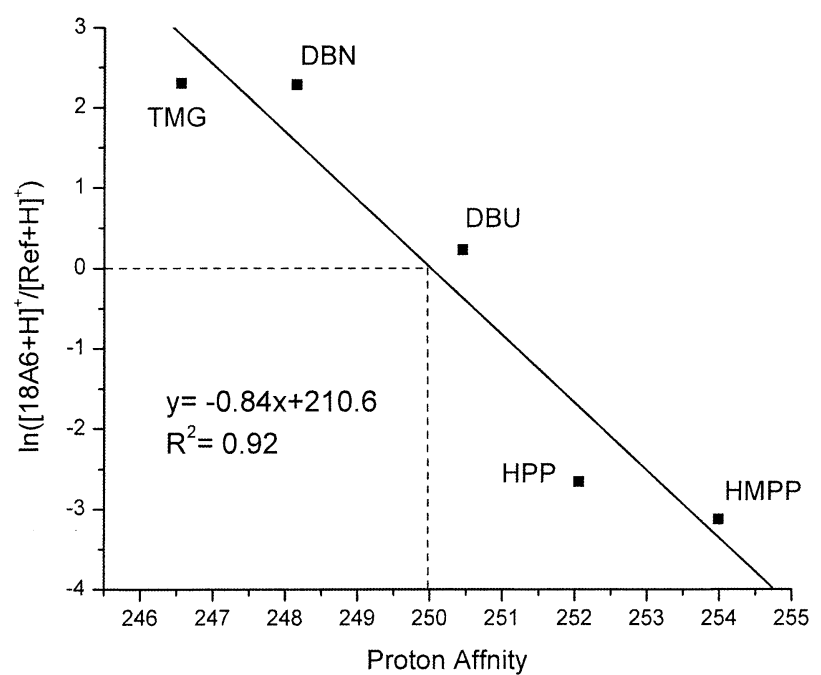

Figure 3. Kinetic method analysis of data acquired using the five reference bases given in Scheme 1. The proton affinity of A18C6 is determined to be $250 \pm 1 \mathrm{kcal} / \mathrm{mol}$. The proton affinities of the reference bases are 246.56, 248.16, 250.45, 252.06, and 253.99 $\mathrm{kcal} / \mathrm{mol}$, respectively [15]. 
mol of this value in the NIST database [16]. PM3 semi-empirical calculations reveal that $[\mathrm{A} 18 \mathrm{C} 6+\mathrm{H}]^{+}$ has a highly symmetrical structure (1). The three most distant oxygens are able to fold back and hydrogen bond with the proton, which is localized on the nitrogen because it is by far the most basic site in the crown. The structure is more compact than that normally associated with A18C6 (2), and the distance between coplanar heteroatoms (between the nitrogen and oxygens in the 7 and 13 positions) shrinks from 5.2 to 3.7 . The gas phase protonation of A18C 6 causes a contraction of the guest cavity, which will lead to the loss of any interaction with a proximate primary amine. This contrasts sharply with the behavior of $18 \mathrm{C} 6$.

The proton affinity of $\mathrm{A} 18 \mathrm{C} 6$ is much greater than that of lysine $(236 \mathrm{kcal} / \mathrm{mol})$ or n-butyl amine $(220.2$ $\mathrm{kcal} / \mathrm{mol}$ ). This suggests that any complex formed in

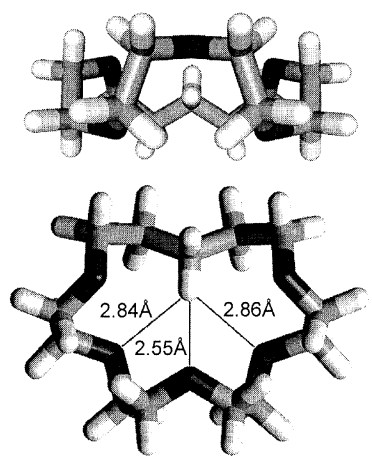

1

Two Views

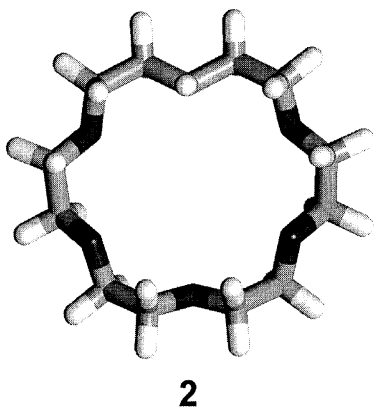

2
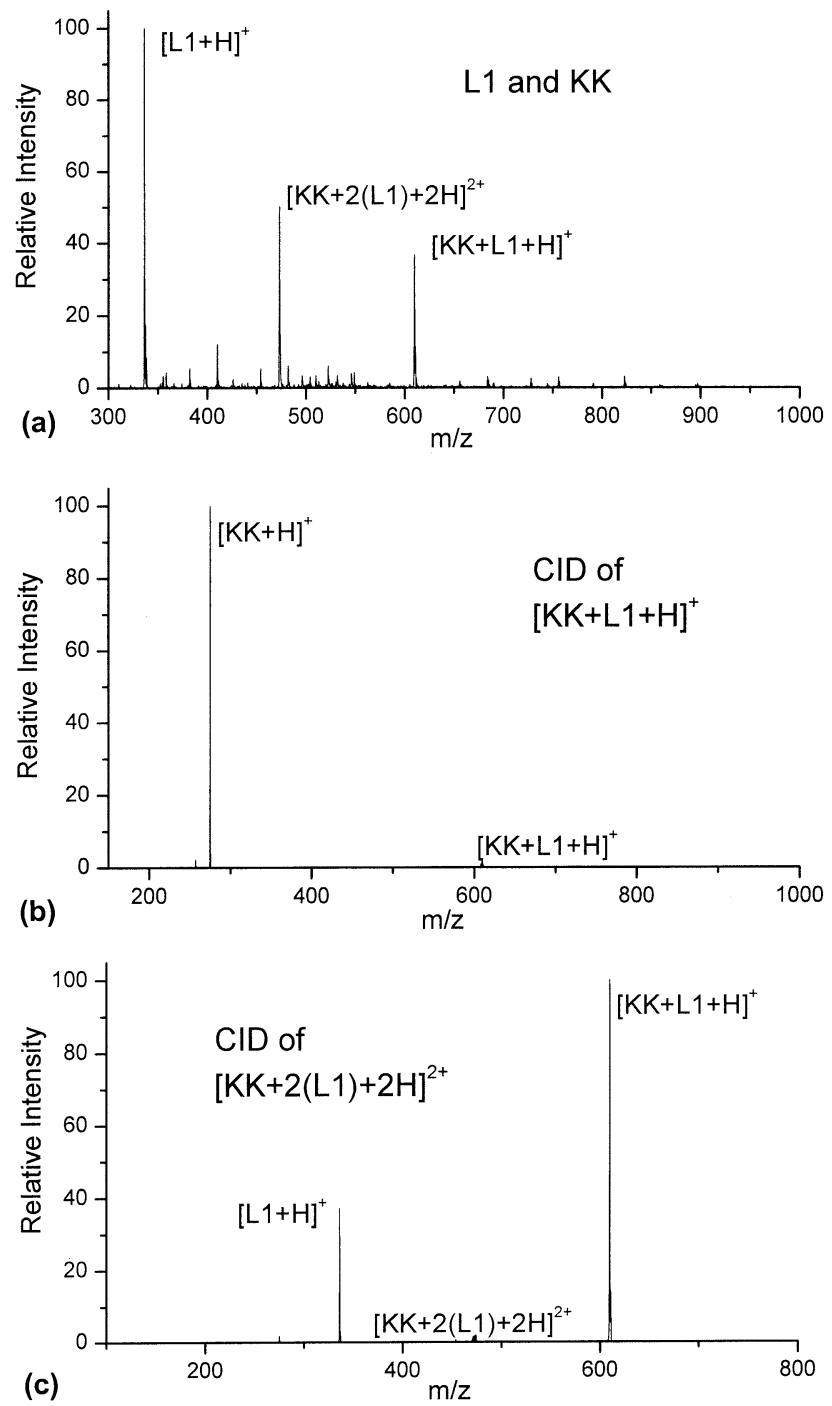

solution between A18C6 and the side chain of lysine will lead to a proton transfer to the A18C6 upon entry to the gas phase. As discussed above, the proton transfer will cause the contraction of the A18C6 guest cavity and dissociation of the complex. Thus the molecular recognition of lysine by A18C6 will result in the A18C6 stripping a proton off of the side chain of lysine. Solution phase data on benzyl ammonium ions indicate that the association of A18C6 with ammonium ions is weak in polar solvents such as water and methanol [17]. The combination of the high proton affinity of A18C6 and its low solution phase association with ammonium ions explain the inability of A18C6 to form any peptide/crown ether adducts in the gas phase. Furthermore, the high proton affinity accounts for the reduced charge state distribution of tetralysine in Figure 1c, because any complexes that are formed will lead to the net loss of charge for lysine-containing peptides.

\section{L1 Forms Adducts with Lysine}

The results presented thus far suggest that if A18C6 is to be used as the base molecule for a lariat crown ether that will form noncovalent adducts with lysine, then the proton affinity of the nitrogen heteroatom must be
Figure 4. (a) ESI-MS of dilysine and L1. Adduct formation with $\mathrm{L} 1$ is observed. (b) CID spectrum of $[\mathrm{KK}+\mathrm{L} 1+\mathrm{H}]^{+}$, resulting in the loss of L1. (c) CID spectrum of $[\mathrm{KK}+2(\mathrm{~L} 1)+2 \mathrm{H}]^{2+}$, resulting in the loss of protonated L1, yielding the complex $[\mathrm{KK}+\mathrm{L} 1+\mathrm{H}]^{+}$.

lower in the lariat crown ether than it is in A18C6. The standard method of attaching side chains results in a tertiary amine at the point of attachment. In general, tertiary amines have higher proton affinities than secondary amines, which would suggest that there would be no adduct formation with such a lariat crown ether. This is indeed the case. Fortunately, amide nitrogens such as that found in n-methyl-acetamide [16] (212.4 $\mathrm{kcal} / \mathrm{mol}$ ) have much lower proton affinities than secondary amines. L1 is a lariat crown ether where the side chain is attached by amidation of the nitrogen heteroatom.

L1 forms non-covalent complexes with the side chain of lysine that can be observed in the gas phase. This is shown in the ESI-MS spectrum for dilysine and L1 in Figure 4 . The adduct peaks are not nearly as intense as those observed for 18C6, but there is sufficient signal to isolate and observe the CID spectra for each adduct 

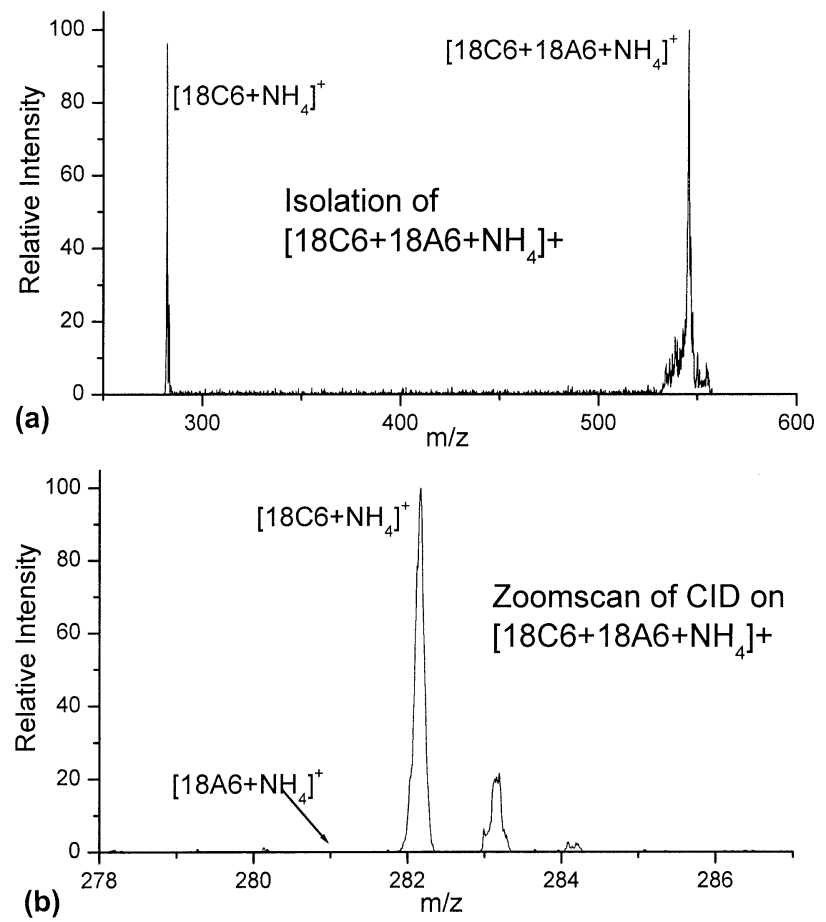

Figure 5. (a) Isolation spectrum for $\left[18 \mathrm{C} 6+\mathrm{NH}_{3}+\mathrm{A} 18 \mathrm{C} 6+\mathrm{H}\right]^{+}$ showing dissociation of the adduct peak to yield the $18 \mathrm{C} 6 \mathrm{ammo}-$ nium adduct exclusively. (b) Zoomscan of the CID spectrum for the $\left[18 \mathrm{C} 6+\mathrm{NH}_{3}+\mathrm{A} 18 \mathrm{C} 6+\mathrm{H}\right]^{+}$peak, again yielding only $\left[18 \mathrm{C} 6+\mathrm{NH}_{3}+\mathrm{H}\right]^{+}$. No protonated A18C6 was observed.

(Figures $4 \mathrm{~b}$ and $4 \mathrm{c}$ ). Molecular modeling at the PM3 semi-empirical level suggests that the methyl-ether oxygen in the side chain of L1 does not participate in the binding of an alkylammonium ion to the lariat crown ether. Therefore, we attribute the enhanced molecular recognition abilities of $\mathrm{L} 1$ relative to $\mathrm{A} 18 \mathrm{C} 6$ to the lower proton affinity of the lariat crown.

\section{Ammonium Ion Affinities}

The kinetic method can be used to determine affinities for ions as well as protons. The relative ammonium ion affinities of a various crown ethers should be correlated with their abilities to form noncovalent adducts with lysine. The $\left[18 \mathrm{C} 6+\mathrm{NH}_{3}+\mathrm{A} 18 \mathrm{C} 6+\mathrm{H}\right]^{+}$complex is very difficult to isolate which suggests that it is weakly bound, and leads to increased baseline noise (Figure $5 a)$. Dissociation of the complex during the process of isolation leads to a very prominent $\left[18 \mathrm{C} 6+\mathrm{NH}_{3}+\mathrm{H}\right]^{+}$ peak in the absence of any excitation. There is no dissociation leading to the $\left[\mathrm{A} 18 \mathrm{C} 6+\mathrm{NH}_{3}+\mathrm{H}\right]^{+}$ion. As shown in Figure 5b, upon collision induced dissociation the ammonium ion is retained entirely by the $18 \mathrm{C} 6$. The $[\mathrm{A} 18 \mathrm{C} 6+\mathrm{H}]^{+}$peak is absent from the CID spectrum as well.

Figure 6a shows the isolation of $\left[\mathrm{L} 1+\mathrm{NH}_{3}+18 \mathrm{C} 6+\mathrm{H}\right]^{+}$. In this case, dissociation of the isolated peak is very minimal. Figure $6 \mathrm{~b}$ shows that the ammonium ion is retained by $18 \mathrm{C} 6$ and suggests that $18 \mathrm{C} 6$ has a much higher ammonium ion affinity than L1. In addition, com-
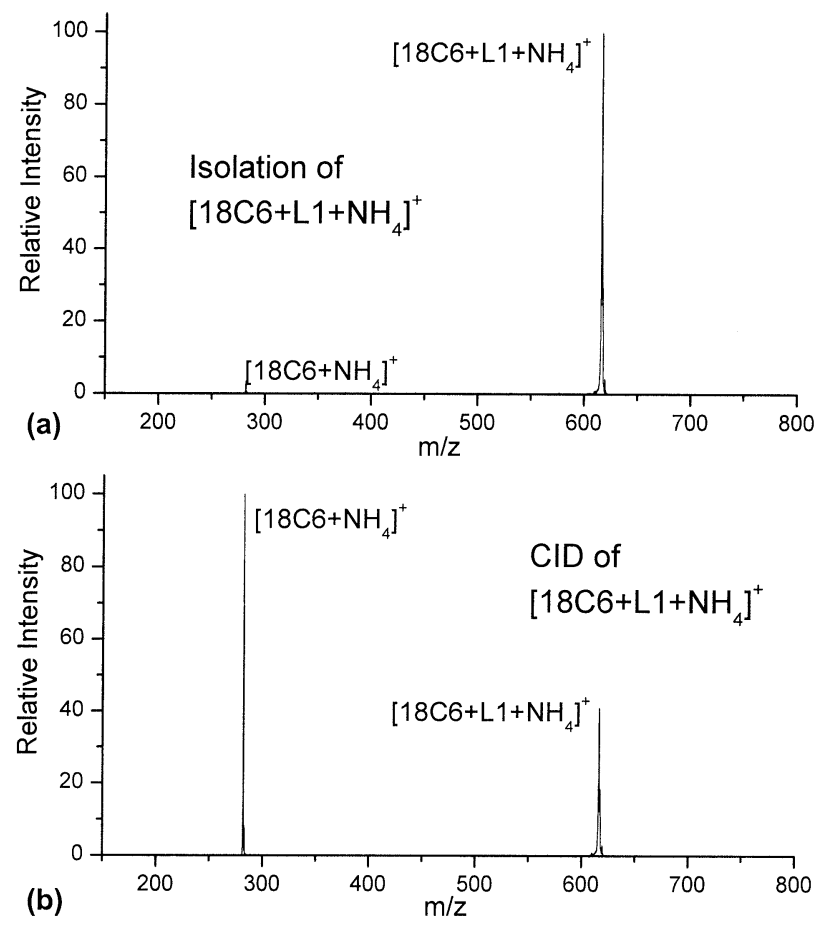

Figure 6. (a) Isolation spectrum for $\left[18 \mathrm{C} 6+\mathrm{NH}_{3}+\mathrm{L} 1+\mathrm{H}\right]^{+}$showing only minimal dissociation of the adduct peak. (b) CID spectrum for the $\left[18 \mathrm{C} 6+\mathrm{NH}_{3}+\mathrm{L} 1+\mathrm{H}\right]^{+}$peak, again yielding only $\left[18 \mathrm{C} 6+\mathrm{NH}_{3}+\mathrm{H}\right]^{+}$.

parison with the data in Figure 5 suggests that L1 has a greater ammonium ion affinity than A18C6. Direct comparison of the ammonium ion affinities of L1 and A18C6 was not possible because we were unable to prepare the appropriate ammonium ion bound dimer. This is attributed to the high proton affinity of A18C6, which leads to protonation of the $\mathrm{A} 18 \mathrm{C} 6$ followed by dissociation prior to detection of the complex. These combined results suggest that the relative ammonium ion affinities for A18C6, L1, and 18C6 as determined qualitatively by the kinetic method are: $18 \mathrm{C} 6 \gg \mathrm{L} 1>18 \mathrm{AA} 6$. Not surprisingly, this indicates that the ammonium ion affinity for a crown ether is correlated with the capacity of that molecule to form noncovalent adducts with lysine.

\section{Conclusions}

The proton affinity of $\mathrm{A} 18 \mathrm{C} 6$ is $250 \pm 1 \mathrm{kcal} / \mathrm{mol}$ as determined by the kinetic method. This proton affinity is unusually high for a secondary amine, and is attributed to a highly symmetrical, hydrogen bond stabilized structure. The high basicity of A18C6 inhibits the formation of noncovalent adducts with lysine containing peptides. A18C6 will deprotonate an alkylammonium ion upon introduction to the gas phase, leading to a net decrease in the charge state of lysine containing peptides, such as observed for tetralysine in Figure 1. It is also likely that the protonation of A18C6 in solution is responsible for the greatly reduced solution phase binding of A18C6 to benzyl ammonium ions relative to $18 \mathrm{C} 6$ 
[17]. The ordering of ammonium ion affinities for the crown ethers determined in the present study, $18 \mathrm{C} 6$ $\gg$ L1>A18C6, parallels their affinity for lysine in small peptides.

The amidation of A18C 6 reduces the proton affinity and allows for the complexation of lysine containing peptides. Relative to 18C6, L1 does not bind to the side chain of lysine in great abundance. This suggests that the intrinsic binding energy to lysine is lower for L1 than it is for $18 \mathrm{C} 6$ and mitigates the utility of such derivatives in the design of effective reagents for the selective cleavage of peptides. Therefore, the lariat side arm of any future crown designed to do chemistry in the gas phase must either enhance the binding energy to the peptide and/or be highly reactive. Otherwise, CID of the complex in question will simply lead to dissociation back into the component molecular species as is the case with dilysine and L1. The Type I lariat crown ethers are likely to be the better choice for the development of biomimetic reagents for selective peptide cleavage, despite the synthetic and conformational limitations imposed by attaching the side chain to carbon.

\section{Acknowledgments}

The authors gratefully acknowledge funding provided by NSF (Grant CHE-9727566) and the Beckman Institute Foundation. The LCQ mass spectrometer was funded by an instrumentation grant from NSF.

\section{References}

1. Schalley, C. A. Int. J. Mass Spec. 2000, 194, 11-39.

2. Schalley, C. A.; Rivera, J. M.; Martin, T.; Santamaria, J.; Siuzdak, G.; Rebek, J. Eur. J. Org. Chem. 1999, 1325-1331.

3. Chen, Q.; Cannell, K.; Nicoll, J.; Dearden, D. V. J. Am. Chem. Soc. 1996, 118, 6335-6344.
4. (a) Julian, R. R.; Hodyss, R.; Kinnear, B.; Jarrold, M. F.; Beauchamp, J. L. accepted for publication in J. Phys. Chem. B, 2001. (b) Counterman, A. E.; Clemmer, D. E. . J. Phys. Chem. $B$ 2001, 105(34), 8092-8096. (c) Cooks, R.G.; Zhang, D.X.; Koch, K.J.; Gozzo, F.C.; Eberlin, M.N. . Anal. Chem. 2001, 73(15), 3646-3655.

5. (a)More, M.B.; Ray, D.; Armentrout, P. B. J. Am. Chem. Soc. 1999, 121, 417-423.(b)Wu, H.-F.; Brodbelt, J. S. J. Inclus. Phenom. Mol. 1994, 18, 37-44.

6. Maleknia, S.; Brodbelt, J. S. J. Am. Chem. Soc. 1993, 115, 2837-3843.

7. Lee, S.-W.; Lee, H.-N.; Kim, H. S.; Beauchamp, J. L. J. Am. Chem. Soc. 1998, 120, 5800-5805.

8. Julian, R. R.; Beauchamp, J. L. Int J. Mass Spectrom. 2001, 210, 613-623.

9. Dishong, D.M.; Diamond, C.J.; Cinoman, M.I.; Gokel, G.W. J. Am. Chem. Soc. 1983, 105(3), 586-593.

10. Schultz, R.A.; Dishong, D.M.; Gokel, G.W. Tetrahedron Lett 1981, 22(28), 2623-2626.

11. Bradshaw, J.S.; Izatt, R.M.; Bordunov, A.V.; Zhu, C.Y.; Hathaway, J.K. In Comprehensive Supramolecular Chemistry, Vol. 1; G. W. Gokel, ed., Pergamon/Elsevier: Oxford, 1996, pp 35-95.

12. Cooks, R. G.; Kruger, T. L. J. Am. Chem. Soc. 1977, 99, 1279-1281.

13. McLuckey, S. A.; Cameron, D.; Cooks, R. G. J. Am. Chem. Soc. 1981, 103, 1313.

14. Mayo, S. L.; Olafson, B. D.; Goddard, W. A. J. Phys. Chem. 1990, 94, 8897-8909.

15. Chu, I.-H.; Zhang, H.; Dearden, D. V. J. Am. Chem. Soc. 1993, $115,5736-5744$.

16. Hunter, E.P.; Lias, S.G. http://webbook.nist.govhttp:// webbook.nist.govAll proton affinities for this paper were taken from the NIST database. "Proton Affinity Evaluation" in NIST Chemistry WebBook, NIST Standard Reference Database Number 69, Eds. W.G. Mallard and P.J. Linstrom, February 2000, National Institute of Standards and Technology, Gaithersburg MD, 20899.

17. Rudiger, V.; Schneider, H.-J.; Solov'ev, V. P.; Kazachenko, V. P.; Raesky, O. A. Eur. J. Org. Chem. 1999, 1847-1856. 